\title{
LYMPHO-EPITHELIOMA OF THE THYMUS NERVOUS AND OTHER CLINICAL SYMPTOMS IN THE ADULT
}

\author{
BY
}

\author{
F. PARKES WEBER and K. BLUM
}

\author{
(RECEIVEd 8TH SePtember, 1942)
}

IN this paper we are concerned, not with the simple tumours-fibroma, lipoma, lymphangioma, lymphosarcoma, round-cell sarcoma-which occasionally (though rarely) arise in the thymus, as in other parts of the body, but with those which arise from the essential epithelioid cells of the thymic medulla associated in greater or lesser proportion with lymphocyte-like cells (probably really lymphocytes), such as constitute the normal thymic cortex. These primary thymic tumours-true "thymomata"may be termed "lympho-epitheliomata" (Grandhomme, 1900; Schmincke, 1921; Regaud, 1921), and are much less often malignant than are the primary lympho-epitheliomata of the tonsils, pharynx, and naso-pharynx (Cappell, 1934; Harvey, Dawson and Innes, 1937). For recent histological accounts of thymic lympho-epitheliomata, see $\mathrm{Wu}$ (1935) and Obiditsch (1937).

The thymic lympho-epitheliomata seem in some cases to exert an endocrine effect, and are specially related to myasthenia gravis. Most important and interesting was the original observation by Weigert (1901) of a thymus tumour in a case of myasthenia gravis in which he wrongly interpreted the "lymphorrhages" in the muscles as tumourmetastases. To these questions we will return in the discussion further on, but for a summary of the literature of the subject we must refer to the recent papers by Gold (1935), Meister (1936), Norris (1936), Miller (1940), Blalock et al. (1941), and Poer (1942).

\section{Case Record}

The patient, Mrs. F. F., aged 58 years, was admitted on 5th November, 1941, with irregular pyrexia of uncertain origin. The history was that after a sore throat 6 weeks ago she had been suffering from pains in various parts. Blood-count: Hæmoglobin, 60 per cent.; erythrocytss, 3,610,000; colour-index, 0.8 ; leucocytes, 9,000 (polymorphs, 53 per cent.; lymphocytes, 40 per cent.; monocytes, 7 per cent.). Blood-sedimentation: first hour, 70; two hours, 120. Blood-culture: negative. Urine: nothing abnormal. By auscultation a blowing systolic murmur could be heard in the left intercostal space close to the sternal margin. X-ray examination of the heart (Dr. F. G. Wood) showed a rounded mass projecting to the left of, and apparently continuous with, the heart shadow and moving with it; right and left oblique views were thought to point to this projection being an enlargement of the pulmonary artery and conus (Fig. 1). Brachial blood-pressure: $135 / 80 \mathrm{~mm}$. Hg. Blood-Wassermann reaction: negative. Ophthalmoscopic examinations (Dr. C. Markus) showed hyperæmia, especially left eye, apparently connected with hyper- metropia. The patient at various times complained of a severe kind of acroparæsthesia and of numbness (no real anæsthesia) of the right lower limb and afterwards of the right upper limb and both lower limbs. Severe cramps were sometimes complained of. The knee-jerks, which were equal and natural on admission, were unequal at the end of November, the left one being greatly exaggerated. In March 1942 the patellar and Achilles reflexes were absent on both sides; the triceps. reflex was absent on the right side, present on the left side; the planter reflex was of the normal flexor type on both sides; no superficial abdominal reflexes were obtained. Both pupils reacted normally. The speech was rather sluggish. Very little tactile responses in either lower limb; some hypersensitiveness to pressure over the sciatic nerve, both sides. The patient tended to keep her knee-joints flexed. Although general asthenia was very marked, no definite characteristic features of myasthenia gravis were noted.

Focal infection was thought of, but no focus could be discovered. There was moderate fever from admission to 25 th November-then a little at the commencemen $\varnothing$ of December and from 10th December to the comb mencement of January 1942. About 5th February there was again fever, and then from 22nd February tos the patient's death on 17th March, 1942, which was due to a final broncho-pneumonia with some decubitus. Frequent profuse night sweatings constituted also a
clinical feature. The last blood-culture yielded a growth of staphylococcus albus. Amongst the drugs tried sulphapyridine on one or two occasions seemed to exert temporary beneficial effect.

\section{Necropsy}

Over the front upper part of the heart and slightly to the left, firmly connected with the fibrous layers of the parietal pericardium, was a bun-shaped mass, about the size of half a large orange, $14 \times 8 \times 6 \mathrm{~cm}$. in measurement (weight after preparation as a museum specimen: $112 \mathrm{gm}$.). The multilocular cystic central portion of the mass had a honeycomb appearance on section; most of the cysts freely communicated with each other and were filled with a slimy, translucent mucoid fluid; their walls had a smooth inner surface. In the upper portion of the "tumour" was a slightly larger cavity, which was filled with what macroscopically appeared to be pus, but no microbes could be detected in a film stained with methylene blue, or by Gram's method.

Thyroid gland: slightly enlarged, showing nodular adenomatous condition, one of the nodules in the left lobe having a calcified capsule. Bronchopneumonia of the lower lobe of the right lung; purulent bronchitis. Nothing specially noteworthy in the other organs: brain, heart, liver, spleen, pancreas, adrenals, kidneys, uterus, ovaries, gastrointestinal tract, larynx. 
Microscopical Examination

The solid part of the mass consisted of a dense collagenous fibrous framework, in which were embedded cellular islands consisting of delicate spindle and epithelioid cells with vesicular nuclei, associated with lymphocyte-like cells as in so-called thymic lympho-epitheliomata (Fig. 2). No Hassal's corpuscles were seen, but at one spot several elongated, slightly curved ("banana-shaped ") vesicular nuclei were noted, grouped together, so as to suggest a entiated in sections stained in other ways. The honeycomb cystic portion of the tumour represented apparently a further stage of aseptic necrotic involution of the lympho-epitheliomatous tissue. The process was probably analogous to the occasional changes in the thymus gland of children leading to the formation of Dubois's " abscesses" or pseudoabscesses formerly supposed to be necessarily connected with congenital syphilis.

Is the mass to be regarded as a real lympho-

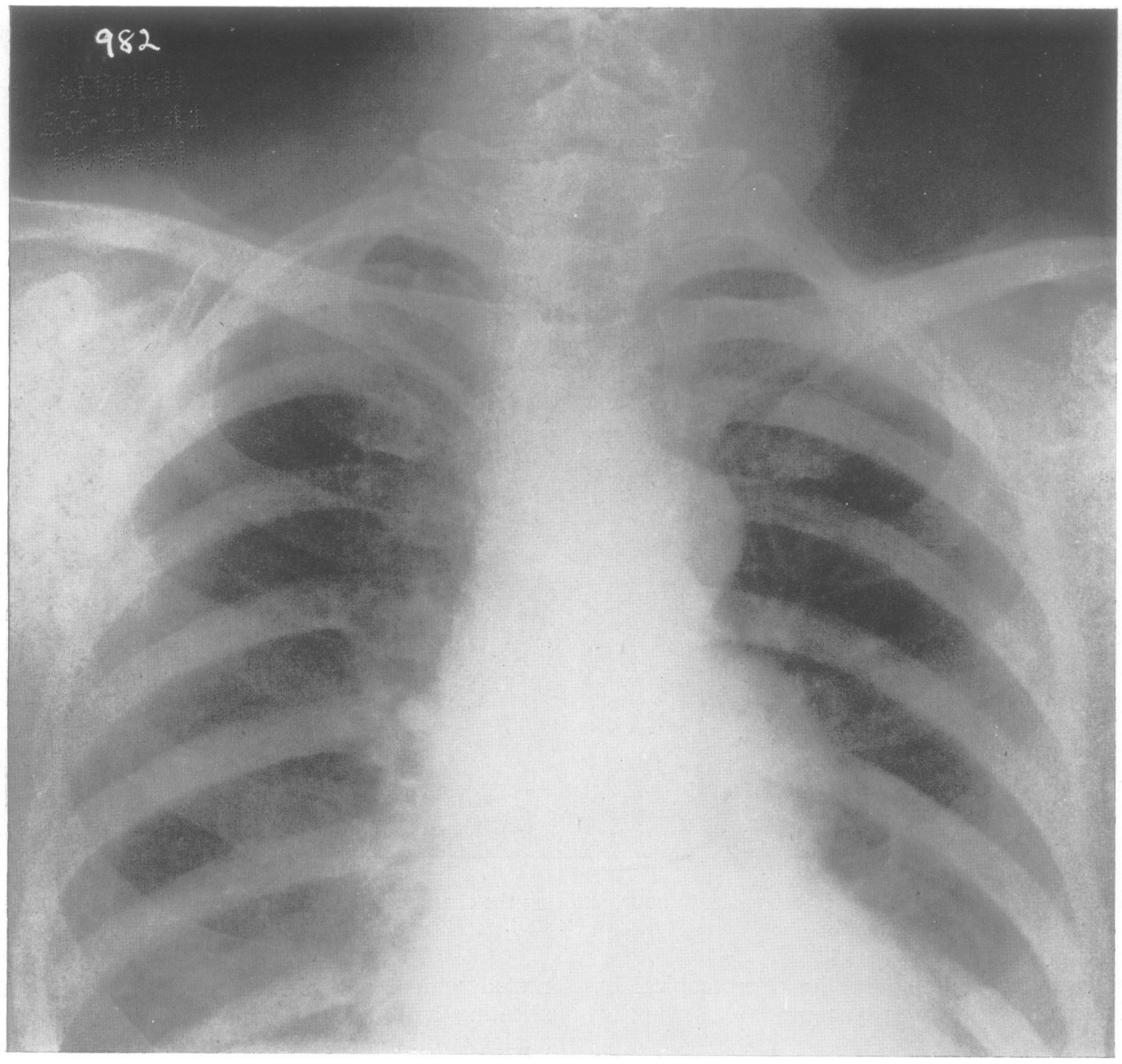

Fig. 1.-Radiogram of the thorax taken on 20th November, 1941.

faint attempt at the formation of a Hassal's corpuscle. In their shape some of the so-called "spindle cells" resemble rather the cells of " oatcell " bronchial carcinoma. Microscopical examination of what macroscopically had appeared to be pus showed that it consisted of this cellular material breaking down ("softened") as a result of (ischæmic?) necrosis. It may be mentioned that a film of this "pseudo-pus" stained with methylene blue showed the presence of a considerable number of tissue mast-cells, which were not clearly differ- epitheliomatous tumour of an ectopic thymus (or thymic " rest") with secondary cystic degenerative changes, as above explained, or is it an example of hypertrophy of an ectopic thymus (or thymic " rest") containing cysts resulting from involutionary focal ischæmic necrotic processes (Kopač, 1939)? The spindle and epithelioid cells resemble those of normal thymic medulla and the lymphocytelike cells resemble those of normal thymic cortexwhich most authors now regard as true lymphocytes -but the grouping of these two constituent types 
of cells is not sufficiently clearly marked out into cortex and medulla to permit the mass to be regarded as the result of mere thymic hypertrophy; nor does the complete absence of Hassal's corpuscles favour the view of mere hypertrophy. The mass must therefore, we think, be regarded as a true primary thymic lympho-epitheliomatous tumour ("thymoma"). Whether the tumour is a primary one of an ectopic thymus or of a thymic " rest " makes no difference from the pathological point of view; we did not specially search for any thymic remnant in the normal position. By our term " ectopic" we do not imply that the position of the tumour, in front of the pericardium, is abnormal for thymic tissue in early childhood. In the present case there were no cells functionally still resemble the cells of simple hyperplasia.

In something like 55 per cent. of cases of myasthenia gravis hypertrophy or primary tumour (lymphoepithelioma) of the thymus has been present, but in reality the percentage is probably considerably higher, for in many cases thymus or thymic tumour has not been sufficiently looked for. On the other hand, myasthenic symptoms may have been overlooked in some cases of thymic tumour in surgical wards (Mann, 1934). Although in our present case characteristic symptoms of myasthenia gravis were absent, it is highly probable that the great general asthenia, the extreme acroparæsthesia, numbness and other nervous symptoms were in some way con-

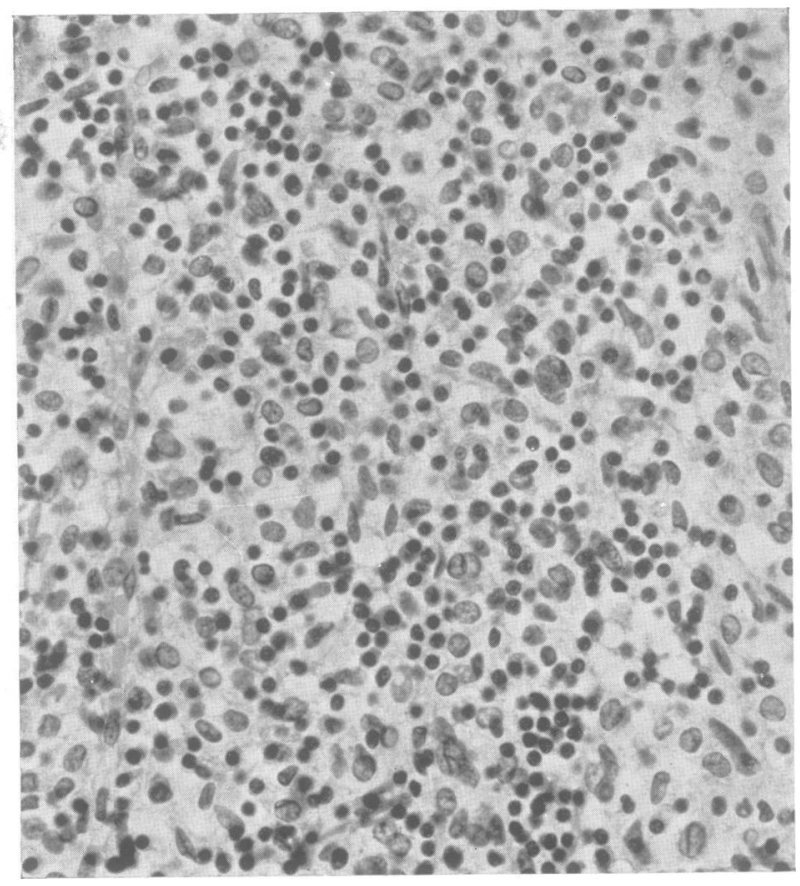

FIG. 2.-Photomicrograph of part of the tumour, showing the characteristic epithelioid and lymphocyte-like cells $(\times 400)$.

metastases and nothing in the microscopical examination pointed to malignancy.

\section{Discussion}

Clinical symptoms from thymic hypertrophy or tumour may of course be mechanical, from local pressure, and in the present case the systolic murmur heard to the left of the sternum was probably due to tumour pressure.

If the thymus is an endocrine organ one would expect that constitutional endocrine symptoms would often result-as they often do in primary tumours of other endocrine organs-from a primary neoplasm arising from the essential (endocrine) cells, that is to say, so long as the neoplastic cells still retain something of the original functional (endocrine) activity, in fact, so long as the neoplastic nected with the thymic tumour. The recurrent sweating and pyrexial periods may possibly, by analogy with what happens in some cases of lymphogranulatosis maligna, be atrributed to the necrotic softening and formation of "pseudo-pus" in the lympho-epithelioma, with resulting toxic absorption. Patients with thymic lympho-epithelioma, according to the literature (Matras and Priesel, 1928; Zajewloschin, 1929 and 1933; Nemenow, 1932; Ercklentz, 1936), have died of pleuritis, empyema, pneumonia, furunculosis, and decubitus. The loss of resistance to toxic-infectious agents culminated in our case with the decubitus and broncho-pneumonia, the latter first manifest 4 days before the patient's death, the former a week earlier. It is possible that the absence of definite symptoms of myasthenia gravis might be due to the diminution of the (pre- 
sumable active) function of the epithelioid cells consequent on the necrotic softening of many of the latter associated with the formation of the "pseudo-pus" and cysts.

In regard to clinical diagnosis the X-ray shadow of a thymic tumour is of great importance. In our case it seemed to move with the pulsation of the great vessels and to be continuous with the heart shadow. The position of the tumour in the anterior mediastinum overlapping the parietal pericardium on the left was not made out during life. In the differential diagnosis during life cardiac aneurysm, pericardial tumour, mediastinal lymphogranuloma, mediastinal gumma, mediastinal phlegmon, and congenital dilatation of the pulmonary artery might be thought of. Had the correct diagnosis been made at an early stage, our case would have been an ideal one, if not for surgical excision of the tumour, at least for treatment by X-rays or radium.

The possible part played by the thymus gland in some cases of Graves's Disease is suggested by the occasional occurrence of myasthenic symptoms in the latter disease and even by satisfactory results of thymectomy (Schumacher and Roth, 1913; Russell Brain, 1938; Adler, 1939). Fraser (1937) recorded the case of a woman suffering from myasthenia gravis and Graves's Disease, who temporarily completely lost her myasthenic ophthalmoplagic symptoms under the influence of prostigmin. Dudgeon and Urquhart (1926) in nine cases of Graves's Disease found muscle "lymphorrhages" similar to those of myasthenia gravis.

It seems that in very rare cases malignant thymoma or primary carcinoma of the thymus may by some unknown process disturb the endocrine balance in such a way as to give rise to symptoms somewhat resembling Cushing's syndrome (Leyton, Turnbull and Bratton, 1931), but into this question of the "Leyton-Turnbull-Bratton syndrome" we cannot enter here.

For help in the microscopical examination we have specially to thank Dr. J. R. Gilmour, Dr. R. W. Scarff, Dr. H. M. Turnbull, Dr. J. G. Greenfield, and Dr. A. H. T. Robb-Smith. We owe the photomicrograph to Dr. Greenfield. The tumour itself is now in the Museum of the Royal College of Surgeons.

\section{REFERENCES}

Adler, H. (1939). Dtsch. med. Wschr., 65, 909.

Blalock, A., Harvey, A. M., Ford, F. R., and Lilienthal, J. L. (1941). J. Amer. med. Ass., 117, 1,529.

Brain, W. R. (1938a). Guy's Hosp. Rep., 88, 125 ; (1938b). Quart. J. Med. (new series), 7, 293 (See p. 311)

Cappell, D. F. (1934). J. Path. Bact., 39, 49.

Dudgeon, L. S., and Urquhart, A. L. (1926). Brain, 49, 182.

Ercklentz, B. W. (1936). Klin. Wschr., 15, 1,393.

Fraser, F. R. (1937). Trans. ophthal. Soc. U.K., 57, 116. Gold, E. (1935). Wien. klin. Wschr., 48, 694.

Grandhomme, F. (1900). Inaug.-Dissert. Heidelberg.

Harvey, W. F., Dawson, E. K., and Innes, J. R. M. (1937). Edinb. med. J. (new series), 44, 549.

Kopač, Z. (1939). Beitr. path. Anat., 102, 560.

Leyton, O., Turnbull, H. M., and Bratton, A. B.( 1931). J. Path. Bact., 34, 635.

Mann, L. (1934). Z Zbl. Chir., 61, 2,384.
Matras, A., and Priesel, A. (1928). Beitr. path. Anat., 80, 270 .

Meister, M. (1936). Klin. Wschr., 15, 1,389.

Miller, H. G. (1940). Arch. Path., 29, 212.

Nemenow, M. I. (1932). Strahlentherapie, 44, 655 (See p. 664).

Norris, E. H. (1936). Amer. J. Cancer, 27, 421.

Obiditsch, R. A. (1937). Virchow's Arch., 300, 319.

Poer, D. H. (1942). Ann. Surg., 115, 586.

Regaud, M. (1921). See Reverchon and Coutard (1921). Bull. Mém. Otorhino-laryngol., Paris, 34, 209.

Schmincke, A. (1921). Beitr. path. Anat., 58, 161.

Schumacher and Roth (1912). Mitt. Grenzgeb. Med. Chir., 25, 746.

Weigert, C. (1901). Neurol. Cbl., 20, 597.

Wu, T. T. (1935). J. Path. Bact., 41, 351.

Zajewloschin, M. N. (1929). Frankfurt Z. Path., 37, 36 ; (1933). Z. ges. Neurol., 148, 28. 